\section{Response latency as a function of free choice or fixed postreedback interval in concept identification}

\author{
LERDY MATTHEWS \\ Idaho State University, Pocattlo. Idaho 83201
}

Sixty-tour Ss were required to learn a three-dimensiona, binary choice concept identification task with either (1) a ixed 2-sec postfeedback interval (PFI) or (2) a free-choice PFI. All Ss were allowed to determine their own response interval $(\mathrm{RI})$. The results indicated no differences in $\mathrm{RI}$ latencies between these groups. However, RI latencies were longer when the stimuli were more complex. PFI latencies did not vary as a function of stimulus complexity. Both RI and PFI latencies were longer following errors and tended to be shorter during reversal-shift transfer task. The free-choice PFI Ss reached criterion in fewer trials than did the 2 -sec PFI Ss. These results were interpreted as supporting a hypothesis that Ss eliminate hypotheses during the PFI and select hypotheses during the RI.

There is considerable evidence that concept identification is facilitated when the postfeedback interval (PFI) is extended (Bourne \& Bunderson, 1963; Bourne, Dodd, \& Justesen, 1965; Roweton \& Davis, 1968). Furthermore, facilitation has been demonstrated when the PFI is extended following either errors only or correct responses only (Bourne, Dodd, Guy, \& Justesen, 1968). The implication of these results is that a longer PFI allows the $S$ a greater opportunity in which to use memory or engage in other problem-solving activity.

Matthews (1972) reasoned that allowing Ss to determine their own PFI following each trial should facilitate learning compared to Ss allowed a short fixed PFI. However, no differences in learning were observed.

A possible reason for the failure to find facilitation using the free-choice PFI paradigm could be attributed to the occurrence of increased problem-solving activity during the response interval when the PFI is short. The response interval (RI) is the period between the presentation of the stimulus and the S's overt response. In view of this possibility, the hypothesis was tested that RI latencies would be longer for Ss on a 2-sec PFI schedule than for Ss allowed a free-choice PFI. Since RI latencies may depend in part upon the discriminability of the stimuli, two levels of stimulus complexity were employed. Furthermore, all Ss were transferred for several trials to a reversal shift task in order to evaluate the hypothesis that both RI and PFI latencies would be shorter during transfer than during presolution due to an improvement in their ability to process information effectively. mopided by the $\mathrm{E}$. This interval was defined as the PFI. They were also instructed to tel! the $E$ when they wanted the next stimulus card to appear. The 2-sec PFI Ss (Group C) were allowed $2 \mathrm{sec}$ following feedback before the presentation of the next card. All stimulus and informative leedback cards were presented manually to the s. Fach $S$ was shown fach of the various geometrieal figures or circles separaitly prior to training.

The various combinations of the stimuli were randomized, and the $S_{s}$ were administered the stimuli in that random order. Ecch of the geometric figures or circles were used about equally often as the relevant dimension. The $\mathrm{Ss}$ were required to reach a criterion of eight successive correct classifications, after which the informative feedback on the ninth trial was appropriate to the value opposite to that previously given and was maintained for 10 trials. The task was terminated after 10 trials in transfer. RESULTS

Sixty-four students from a beginning psychology course at Idaho State University served as Ss. Participation in at least one experiment was a part of their course requirement. Experimental conditions were randomized, and Ss were assigned to their respective conditions upon arrival for testing.

\section{MATERIALS}

Stimuli were drawn on $3 \mathbf{x} 5$ in. white index cards in black ink. For the easy discrimination stimuli (Esy), three different geometric figures were used and were either filled or open. The three figures were circle, square, and triangle located in vertical order on the card. For the difficult discrimination stimuli (Dff), three circles were used and each was cross-hatched in a different direction at the top or bottom half of each circle. Three different geometric figures or circles always appeared for a given trial, but in one of the various combinations of filled or open or cross-hatched at the top or bottom of the circle. A stopwatch was used for timing.

\section{DESIGN AND PROCEDURE}

The Ss were instructed that it was their task to learn which of the several geometric figures or circles presented to them would lead to a correct classification. They were informed that one of the figures or circles could be classified into an "A" and "B" category and that they were to attempt to learn which one. After the presentation of the stimulus card, Ss were allowed to take as much time as they wanted in which to respond. This interval was defined as the RI. The free-choice PFI Ss (Group FC) were given the additional instruction that they could take as long as they wanted following the informative feedback
Average response latencies (RL) were computed for each $\mathrm{S}$ by summing the latencies following error or correct responses prior to criterion and dividing by the respective number of error or correct responses made by that $\mathrm{S}$. The RLs following correct responses during criterion were computed separately, as were those during transfer. Since the analysis consisted of comparing Ss on RLs following both error and correct responses, the scores of 10 Ss were not used because these $S$ s failed to make at least one error and one correct response prior to criterion. All data analyses involving latency data were undertaken using a reciprocal transformation. The means and SDs of RLs following error or correct responses during presolution, criterion, and transfer are presented in Table 1.

A 2 by 2 by 2 by 2 analysis of variance design was used to evaluate the RL data. Independent observation comparisons were made between free-choice and fixed 2-sec PFI groups and between groups receiving Esy stimuli and Dff stimuli. Repeated observation comparisons were made between RLs following correct classifications and following error classifications and between precriterion and transfer.

The analysis resulted in significantly longer RLs for groups receiving Dff stimuli compared to groups receiving Esy stimuli $[F(1,50)=6.17, p<.05]$, longer RLs following error classifications compared to correct classifications $[F(1,150)=22.65$, $\mathrm{p}<.01]$, and longer RLs during precriterion compared to transfer $[F(1,150)=27.35, \quad p<.01]$.

\section{Response Latencies}


Table 1

Means and SDs of RI Latencies* Following Error and Correct Responses

\begin{tabular}{|c|c|c|c|c|c|}
\hline & & & Presolution & Criterion & Transfer \\
\hline \multicolumn{6}{|l|}{ Group C } \\
\hline \multirow[b]{2}{*}{ EY } & \multirow[t]{2}{*}{ Error } & Mean & 3.20 & - & 2.44 \\
\hline & & SD & 1.38 & - & 1.22 \\
\hline$N=12$ & Correct & $\begin{array}{l}\text { Mean } \\
\text { SD }\end{array}$ & $\begin{array}{l}3.04 \\
1.40\end{array}$ & $\begin{array}{r}2.00 \\
.86\end{array}$ & $\begin{array}{r}1.90 \\
.65\end{array}$ \\
\hline \multirow{2}{*}{$\begin{array}{l}\text { DFF } \\
N=16\end{array}$} & Error & $\begin{array}{l}\text { Mean } \\
\text { SD }\end{array}$ & $\begin{array}{l}4.13 \\
2.04\end{array}$ & - & $\begin{array}{l}4.62 \\
3.30\end{array}$ \\
\hline & Correct & $\begin{array}{l}\text { Mean } \\
\text { SD }\end{array}$ & $\begin{array}{l}3.87 \\
2.40\end{array}$ & $\begin{array}{r}2.25 \\
.85\end{array}$ & $\begin{array}{l}2.68 \\
1.00\end{array}$ \\
\hline \multicolumn{6}{|l|}{ Group FC } \\
\hline \multirow{2}{*}{$\begin{array}{l}E Y \\
N=11\end{array}$} & Error & $\begin{array}{l}\text { Mean } \\
\text { SD }\end{array}$ & $\begin{array}{l}3.88 \\
1.29\end{array}$ & - & $\begin{array}{l}3.64 \\
2.37\end{array}$ \\
\hline & Correct & $\begin{array}{l}\text { Mean } \\
\text { SD }\end{array}$ & $\begin{array}{l}2.63 \\
1.15\end{array}$ & $\begin{array}{l}2.58 \\
1.68\end{array}$ & $\begin{array}{l}2.99 \\
1.82\end{array}$ \\
\hline \multirow{2}{*}{$\begin{array}{l}D F F \\
N=15\end{array}$} & Error & $\begin{array}{l}\text { Mean } \\
\text { SD }\end{array}$ & $\begin{array}{l}5.33 \\
2.60\end{array}$ & - & $\begin{array}{l}3.48 \\
2.31\end{array}$ \\
\hline & Correct & $\begin{array}{l}\text { Mean } \\
\text { SD }\end{array}$ & $\begin{array}{l}3.90 \\
1.73\end{array}$ & $\begin{array}{l}2.09 \\
1.35\end{array}$ & $\begin{array}{r}2.27 \\
.71\end{array}$ \\
\hline
\end{tabular}

* Latency measured in seconds.

Table 2

Means and SDs of PFI Latencies* Following Error and Correct Responses

\begin{tabular}{|c|c|c|c|c|c|}
\hline & & & Presolution & Criterion & Transfer \\
\hline \multirow{2}{*}{$\begin{array}{l}E Y \\
N=11\end{array}$} & Error & $\begin{array}{l}\text { Mean } \\
\text { SD }\end{array}$ & $\begin{array}{l}5.27 \\
2.72\end{array}$ & - & $\begin{array}{l}5.58 \\
2.69\end{array}$ \\
\hline & Correct & $\begin{array}{l}\text { Mean } \\
\text { SD }\end{array}$ & $\begin{array}{l}4.08 \\
1.78\end{array}$ & $\begin{array}{l}2.67 \\
1.55\end{array}$ & $\begin{array}{l}2.50 \\
1.26\end{array}$ \\
\hline \multirow{2}{*}{$\begin{array}{l}\text { DFF } \\
N=16\end{array}$} & Exror & $\begin{array}{l}\text { Mean } \\
\text { SD }\end{array}$ & $\begin{array}{l}4.52 \\
2.79\end{array}$ & - & $\begin{array}{l}4.88 \\
3.49\end{array}$ \\
\hline & Correct & $\begin{array}{l}\text { Mean } \\
\text { SD }\end{array}$ & $\begin{array}{l}4.10 \\
2.81\end{array}$ & $\begin{array}{l}2.47 \\
1.53\end{array}$ & $\begin{array}{l}3.01 \\
2.54\end{array}$ \\
\hline
\end{tabular}

*Latency measured in seconds.

However, RLs were not significantly longer for the fixed 2-sec PFI groups compared to the free-choice PFI groups.

\section{Postfeedback Latencies}

Average postfeedback latencies (PFL) were computed in the same manner as RLs, and the scores of five Ss were not used because those $S$ s failed to make at least one error and one correct response prior to criterion. The means and SDs of PFLs following errors and correct responses during presolution, criterion, and transfer are presented in Table 2.

A 2 by 2 by 2 analysis of variance design was used to evaluate the PFL data. Independent observation comparisons were made between groups receiving Esy stimuli and Dff stimuli. Repeated observation comparisons were made between PFLs following correct classifications and error classifications and between precriterion and transfer.

Significantly longer PFLs were found following errors compared to correct classifications $[\mathrm{F}(1,74)=$ 29.59, p <.01] and longer PFLs during precriterion compared to transfer $[F(1,74)=16.24, p<.01]$. There was also a significant increase in the free-choice PFI Ss to engage in problem-solving activity.

The question arises, however, as to why Ss did not lengthen their RI in order to compensate for the short PFI. This question may be partially answered if it is hypothesized that somewhat different problem-solving activity occurs during the PFI and the RI. Three findings in the present study are relevant to this suggestion. First, learning was facilitated with the free-choice PFI. Second, there were no differences in RI latencies between free-choice and 2-sec PFI Ss. And third, only RI latencies were significantly longer for the more complex stimuli. The first and second of these findings support a hypothesis that Ss engage in hypothesis elimination primarily during the PFI but not during the RI. The third findings suggests that during the RI the $\mathbf{S}$ is oriented toward stimulus discrimination activity and hypothesis selection. These interpretations rest upon the assumption that hypothesis elimination is the primary factor responsible for facilitated acquisition, a view consistent with current theories of concept identification (Levine, 1966; Trabasso \& Bower, 1966).

The findings that $S s$ chose longer PFI and RI latencies following errors is also consistent with this interpretation. During the PFI, if the previous response was correct, the $S$ does not have to eliminate any hypotheses. However, following an error, the $S$ must eliminate and redefine his set of possible hypotheses, which requires a greater length of time. During the RI, if the previous response was correct, the $S$ can simply maintain the same hypothesis as on the previous trial. But following an error, he must choose a new hypothesis from the redefined set of hypotheses, which also requires more time. Furthermore, the finding that both RI and PFI latencies were shorter during transfer suggests that $S$ become more efficient in making each of these respective decisions.

The conclusion that Ss eliminate hypotheses primarily during the PFI and select a new hypothesis during the RI also accounts for the facilitated

Table 3

Means and SDs of Total Instances to Criterion for Groups C, FC EY, and DFF The results of this study do not lengthen their RI when the PFI is short. However, in contrast to the Matthews (1972) study, Ss who were allowed a free-choice PFI learned the relevant dimension in fewer trials compared to Ss on a 2-sec PFI schedule. The reason for the facilitation may be due to the increased opportunity on the part of

\begin{tabular}{|c|c|c|c|}
\hline & & $\begin{array}{c}\text { Group } \\
\text { C }\end{array}$ & $\begin{array}{c}\text { Group } \\
\text { FC }\end{array}$ \\
\hline EY & $\begin{array}{l}\text { Mean } \\
\text { SD } \\
\text { N }\end{array}$ & $\begin{array}{l}34.00 \\
30.78 \\
13\end{array}$ & $\begin{array}{l}18.00 \\
21.32 \\
15\end{array}$ \\
\hline DFF & $\begin{array}{l}\text { Mean } \\
\text { SD } \\
\mathbf{N}\end{array}$ & $\begin{array}{l}45.62 \\
37.31 \\
16\end{array}$ & $\begin{array}{l}24.75 \\
17.48 \\
16\end{array}$ \\
\hline
\end{tabular}


performance found in those studies in which a fixed PFI was allowed (Bourne et al, 1965, 1968). The only difference between these studies and the present one is that Ss are not forced to wait for a prescribed length of time before the next stimulus is presented.

However, this conclusion may be restricted to only those experimental procedures in which the stimuli are continually present during the RI immediately prior to responding. Roweton \& Davis (1968) found that if the period between stimulus offset and the $S$ 's response is increased, performance is improved. It is difficult to interpret this finding other than to speculate that perhaps when the stimulus was not present Ss used the time for additional hypothesis elimination

Additional support other than latency data is required to substantiate the conclusion offered for these results. A direct assessment of trial-to-trial changes in Ss' hypothesis set sizes as a function of each of the PFI and RI periods is required.

\section{REFERENCES}

BOURNE, L., \& BUNDERSON, C. Effects of delay of informative feedback and length of post-feedback interval on concept identification. Journal of Experimental Psychology, 1963,65, $1-5$. BOURNE, L., DODD, D., GUY. E., \& JUSTESEN, D. Response contingent intertrial intervals in concept identification. Journal of Experimental Psychology, 1968,76, 601.608.
BOLRNE L DODD D A JUSTESEX D. Concept identification: The tefects at varying length and informational components of the intertrial interval. Journal of Experimental Psychology. $1965,69,624-629$

LEVINE, II. Hypothesis behavior by humans during discrimination learning. Journal of Experimental Psychology. 1966, 71, 331-336.

MATTHEWS, L. Subject determined post-feedback interval in audtory concept identification. Psychonomic Science, 1972, 26, 193-194.

ROWETON, W., \& DAVIS, G, Effects of preresponse interval, post-informative feedback interval, and problem difficulty on the identification of concepts. Journal of Experimental Psychology, 1968, 78, 642-645.

TRABASSO. T, \& BOWER, G. Presolution dimensional shifts in concept identification: A test of the sampling with replacement axiom in all-or-none models. Journal of Mathematical Psychology, 1966, 3. 163-173. 